\title{
Information Articles
}

\section{The 33rd Symposium on Powder Technology}

The 33rd Symposium on Powder Technology was held on Friday, August 20 at Senri Hankyu Hotel under the auspices of the Hosokawa Powder Technology Foundation with the support of Hosokawa Micron Corporation. The planning of this symposium including the selection of the main subject and speakers was made by the Council of Powder Technology, Japan, supported by Hosokawa Micron Corp.
The symposium this year was also very successful with the attendance of more than 250 with about 25 academic people. The main subject this year was "Powder Technology for the Creation of New Business". In the one-day symposium, there were six presentations including the one given by Mr. Masuo Hosokawa entitled "Globalization of Powder Technology and Its Future Prospect". He has been the vicepresident of this Council for a long time.

\section{The 33rd Symposium on Powder Technology}

Theme: "Powder Technology for the Creation of New Business"

Session 1 To seek for the way for the Japanese Industries to take

Chairperson: Prof. K. Miyanami (Osaka Pref. Univ.)

- Point of view of industrial economical strategy

Mr. Yuji Hosoya for the future

- Application of powder technology to

(The Ministry of Trade and Industry) pharmaceutical particle design

Prof. Yoshiaki Kawashima

(Gifu College of Pharmacy)

Session 2 KONA award commemorative lectures Chairperson: Prof. Yasuo Kousaka (Osaka Pref. Úniv.)

- Research of particle electric charging and Prof. Hiroaki Masuda potentiality of its application

(Kyoto Univ.)

- Mechanism of soft mechanochemical reaction and new concept of creation of new material

Prof. Mamoru Senna

(Keio Univ.)

\section{Session 3 To learn from the successful cases}

Chairperson: Prof. Hitoshi Emi (Kanazawa Univ.)

- Environmental problems and creation of new

Mr. Negoro Isao business

- Globalization of Powder Technology and (Negoro Sangyo)

Its Future Prospect

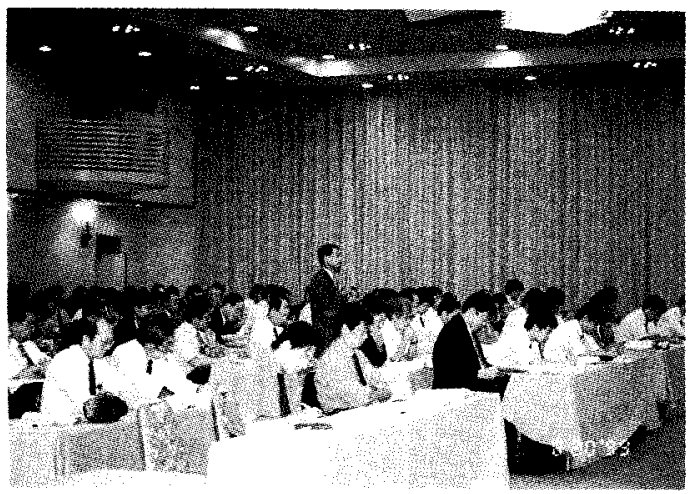

